\title{
Ragam Pola Tabuhan Instrumen Gambang Pada Musik Gambang Semarang
}

\author{
Abdul Rachman', Pramot Teangtrong ${ }^{2}$, Phakamas Jirajaruphat ${ }^{3}$, Udi Utomo ${ }^{4}$, Syahrul \\ Syah Sinaga $^{5}$, Ibnu Amar Muchsin ${ }^{6}$, Sabrina Firda Sokhiba ${ }^{7}$
}

1. Pendidikan Sendratasik, Fakultas Bahasa dan Seni, Universitas Negeri Semarang, Indonesia

2. Music Department, Suan Sunandha Rajabhat University, Bangkok, Thailand

3. Thai Dramatic Arts, Suan Sunandha Rajabhat University, Bangkok, Thailand

4. Pendidikan Sendratasik, Fakultas Bahasa dan Seni, Universitas Negeri Semarang, Indonesia

5. Pendidikan Sendratasik, Fakultas Bahasa dan Seni, Universitas Negeri Semarang, Indonesia

6. Pendidikan Sendratasik, Fakultas Bahasa dan Seni, Universitas Negeri Semarang, Indonesia

7. Pendidikan Sendratasik, Fakultas Bahasa dan Seni, Universitas Negeri Semarang, Indonesia

$$
\text { dulkemplinx@mail.unnes.ac.id }{ }^{1 *}
$$

Gambang Semarang merupakan salah satu musik tradisi Indonesia yang tumbuh dan berkembang di kota Semarang, Jawa Tengah. Musik Gambang Semarang memiliki instrumen yang terbuat dari kayu yang menjadi ciri khas dari musik Gambang Semarang itu sendiri yaitu Gambang. Instrumen Gambang memiliki ragam pola tabuhan khas yang bias memberi nuansa pada musik Gambang Semarang. Tujuan penelitian ini adalah untuk mengetahui dan mendeskripsikan ragam pola tabuhan instrumen Gambang pada musik Gambang Semarang. Metode penelitian yang digunakan adalah kualitatif dengan pendekatan etnomusikologi. Teknik pengumpulan data dilakukan dengan teknik observasi, wawancara, studi dokumen, dan Focussed Group Discussion. Analisis data dilakukan dengan tahapan reduksi data, klasifikasi data, dan penyimpulan. Hasil penelitian menunjukkan bahwa pola tabuhan instrumen gambang pada musik Gambang Semarang terdiri dari pola tabuhan gembyang nglagu oktaf, dan pola garap cengkok ajeg. Masing-masing pola tabuhan dari instrumen gambang tersebut melibatkan rangkaian nada-nada sesuai dengan seleh-nya. Karena terpengaruh seleh dari melodi lagu utama maka pola tabuhan gembyang nglagu oktaf dan pola tabuhan garap cengkok ajeg memiliki enam seleh yaitu seleh do, seleh re, seleh mi, seleh sol, dan seleh la.

Kata kunci : Ragam, Pola Tabuhan, Instrumen, Musik, Gambang Semarang

\section{The Variety of Gambang Instrument Playing Patterns of Gambang Semarang Music}

Gambang Semarang is one of the traditional Indonesian music that grows and develops in the city of Semarang, Central Java. Gambang Semarang music has an instrument made of wood which is the hallmark of Gambang Semarang music itself, namely Gambang. The Gambang instrument has a variety of distinctive accompaniment patterns that can give nuance to the music of Gambang Semarang. The purpose of this study was to identify and describe the various patterns of accompaniment of the Gambang instrument in Semarang's Gambang music. The research method used is qualitative with an ethnomusicological approach. Data collection techniques were carried out by means of observation, interviews, document studies, and Focused Group Discussion. Data analysis was carried out with the stages of data reduction, data classification, and conclusions. The results showed that the accompaniment pattern of the Gambang instrument in Gambang Semarang music consisted of an accompaniment pattern of gembyang nglagu oktaf, and a garap cengkok ajeg pattern. Each accompaniment pattern of the Gambang instrument involves a series of tones according to its seleh. Due to the influence of the melody of the main song, the accompaniment pattern of gembyang nglagu octaf and the accompaniment pattern of garap cengkok ajeg has six selehs, namely seleh do, seleh re, seleh mi, seleh sol, and seleh la.

Keywords : Variety, Playing Pattern, Instrument, Music, Gambang Semarang 
(C) 2021 The Author(s). Published by Pusat Penerbitan LP2MPP Institut Seni Indonesia Denpasar. This is an open-access article under the CC BY-NC-SA license

\section{PENDAHULUAN}

Semarang merupakan sebuah kota multikultur yang terletak di pesisir utara dan merupakan ibu kota dari provinsi Jawa Tengah. Karena letaknya di pesisir utara, menurut sejarah kota Semarang merupakan salah satu pelabuhan penting di pulau Jawa. Tidak heran jika Semarang dikunjungi oleh berbagai etnis seperti Bugis, Melayu, bahkan warga negara asing seperti Cina, Arab, India, Armenia, dan Eropa. Pada umumnya mereka datang ke Semarang untuk memperbaiki kapal serta berdagang. Hal itulah yang menjadikan Semarang sebagai kota yang plural. Seperti yang dikatakan oleh (Ardana, 2009) bahwa pluralitas budaya mewujudkan keragaman bentuk seni tradisional yang disertai dengan keragaman bentuk dan fungsinya. Serta yang dikatakan oleh (Salim, 1999) bahwa keragaman etnis akan memunculkan sebuah budaya baru yang kemungkinan dipengaruhi oleh budaya-budaya sebelumnya. Dengan kondisi tersebut, maka terjadilah ruang interaksi antar budaya, sehingga muncul budaya hibrid. Meskipun orang Jawa adalah kelompok terbesar, mereka tidak dominan secara budaya dengan orang Cina dan Arab. Budaya Semarang kemudian diproyeksikan sebagai sebuah bangunan yang tersusun dari unsur-unsur budaya ketiga etnis tersebut, yang menjadikannya unik jika dibandingkan dengan budaya pesisir lainnya di Jawa Tengah. Sebagai kota yang multikultur tentunya hal ini mempengaruhi kehidupan kesenian di kota Semarang. Artinya, sebagai konsekuensi dari keragaman etnis yang ada di Semarang maka kesenian yang tumbuh dan berkembang di Semarang merupakan akulturasi dari etnis-etnis yang ada terutama tiga etnis yang mendominasi yaitu etnis Jawa, Tionghoa, dan Arab. Salah satu kesenian tradisional yang merupakan hibridasi dari beberapa etnis tersebut adalah kesenian Gambang Semarang (Amanah, 2009; Graaf, 1998; Graaf \& Pigeaud, 1989; Puguh, 2000; Utama \& Puguh, 2013; Yuliati, 2013).

Gambang Semarang adalah seni pertunjukan tradisional yang lahir dan berkembang di Semarang pada dekade ketiga abad XX. Seni pertunjukan ini merupakan salah satu bentuk integrasi budaya antara budaya Jawa dan Cina dan menjadi identitas budaya yang dimiliki dan menjadi kebanggaan masyarakat kota Semarang. Musik dan vokal merupakan unsur utama dalam pertunjukan gambang semarang, sehingga kedua unsur itu ada dalam hampir seluruh penampilannya meskipun pada penyajiannya secara keseluruhan juga menampilkan drama, tari-tarian dan lawak. Seni pertunjukan ini sering ditampilkan pada berbagai acara seperti tahun baru Imlek di beberapa klenteng, acara pernikahan, karnaval Dugderan (acara menyambut bulan Ramadhan/Puasa), acara penyambutan wisatawan asing, dan acara-acara resmi kota Semarang lainnya. Gambang Semarang disebut sebagai budaya hibrida antara unsur budaya Tionghoa dan Jawa karena beberapa hal yang diantaranya adalah pelaku seninya yang biasanya terdiri dari etnis Tionghoa dan Jawa, alat musik yang digunakan, dan tangga nada (scale) yang digunakan yang cenderung menggunakan pentatonis Cina akan tetapi pentatonis Cina dengan kaidah musik barat yaitu do re mi sol la. Biasanya musik tradisional kedaerahan memiliki sistim laras yang bisa berbeda-beda satu sama lain, seperti yang diungkapkan oleh (Wimbrayardi \& Parmadi, 2021) bahwa skala pelarasan musik tradisional antara satu daerah dengan yang lain cenderung berbeda karena pelarasannya menggunakan kupingan dan bukan kaidah musik barat. Berbeda dengan musik Gambang Semarang yang justru menggunakan kaidah pelarasan musik barat. Alat musik dalam Gambang Semarang terdiri atas tiga alat musik rebab Cina seperti Kongahian, Tehian, Sukong, dan alat musik tiup yaitu Suling. Sedangkan alat musik Jawa dalam Gambang Semarang adalah Gambang, Bonang, Kendang, Kecrek, Kempul, dan Gong (Puguh, 2000; Raharjo et al., 2021; Raharjo \& Arsih, 2019; Sadtiti, 2016; Utama \& Puguh, 2013; Yuliati, 2013).

Pada setiap musik tradisi tentunya tidak lepas dari pola iringan yang biasanya cenderung khas, begitu pula yang terjadi pada musik Gambang Semarang. Pola iringan musik Gambang Semarang terbentuk dari pola tabuhan dari beberapa instrumen yaitu Gambang, Bonang, Kendang, Kecrek, Kempul, dan Gong. Masing-masing dari instrumen tersebut memiliki pola tabuhan yang kemudian saling member nuansa antara alat musik yang satu dengan yang lain sehingga menjadi sebuah ritme yang harmonis dan indah. Diantara alat musik dalam Gambang Semarang instrumen yang paling menjadi ciri khas musik tersebut adalah instrumen Gambang. Gambang merupakan salah satu instrumen pokok musik Gambang Semarang yang terbuat dari kayu yang berbentuk bilahan-bilahan panjang yang disusun secara urut dari ukuran terpanjang hingga terpendek dan diletakkan di atas rancakan yang bentuknya menyerupai peti (Puguh, 2000; Sadtiti, 2016; Supanggah, 2002, 2009). Instrumen Gambang pada musik Gambang Semarang memiliki beragam pola tabuhan yang dimainkan oleh kedua tangan 
pemain yang biasanya kedua tangan sang pemain bisa memainkan pola yang sama akan tetapi juga terkadang memainkan pola yang berbeda satu sama lain. Pola tabuhan instrumen Gambang juga memainkan unsur melodi yang dipengaruhi dari melodi lagu vokal. Selain itu biasanya antara pemain Gambang yang satu dengan yang lain memiliki gaya ataupun interpretasi yang berbeda dalam memainkan pola tabuhannya, akan tetapi secara prinsip memang pada dasarnya sama. Hal inilah yang membuat menarik dari musik Gambang Semarang itu sendiri terlepas gaya yang dimainkan oleh sang pemain merupakan cirri khas gaya permainan Semarangan. Berdasarkan fenomena tersebut peneliti ingin membahas tentang ragam pola tabuhan instrumen Gambang dalam musik Gambang Semarang.

Penelitian mengenai musik Gambang Semarang sudah pernah dilakukan oleh para peneliti sebelumnya, seperti yang dilakukan oleh (Utama \& Puguh, 2013) yang meneliti tentang sejarah dan perkembangan musik Gambang Semarang. Menurut Utama dan Puguh seni pertunjukan Gambang Semarang merupakan kesenian hibrid yang muncul tidak lepas dari komunitas-komunitas multi etnis yang ada di kota Semarang yang kemudian tumbuh dan berkembang dan terus beradaptasi dengan jaman sehingga kesenian ini menjadi salah satu kesenian kebanggan kota Semarang. Pembahasan ini juga didukung oleh penelitian yang dilakukan oleh (Sadtiti, 2016) akan tetapi lebih memfokuskan pada dinamika keberadaan kesenian Gambang Semarang di kota Semarang. Berikutnya penelitian yang dilakukan oleh (Raharjo et al., 2021) yang membahas tentang pelestarian musik Gambang Semarang melalui enkulturasi kepada masyarakatnya. Menurut Raharjo pelestarian musik Gambang Semarang bisa dilakukan dengan enkulturasi kepada generasi penerus seperti remaja dan anak-anak baik di sekolah maupun di luar sekolah. Beberapa penelitian di atas dijadikan dasar pijakan oleh peneliti dari sejarah, perkembangan, dinamika, dan pelestariannya. Akan tetapi pada bab ini peneliti lebih memfokuskan pada pembahasan keragaman pola tabuhan terutama instrumen Gambang pada musik Gambang Semarang.

\section{METODE PENELITIAN}

Metode yang digunakan dalam penelitian ini adalah metode kualitatif dengan pendekatan etnomusikologi. Metode ini dilakukan dengan cara menjelaskan fenomena yang terjadi dalam konteks penelitian, mendeskripsikannya dalam bentuk katakata tertulis yang diperoleh dari pengamatan terhadap fenomena tersebut untuk mengetahui ragam pola tabuhan instrument Gambang pada musik Gambang Semarang. Pengumpulan data menggunakan tiga teknik yaitu observasi, wawancara, studi dokumen, dan Focussed Group Discussion. Metode observasi dilakukan dengan cara mengamati, menelaah, memahami fenomena yang dilakukan dengan menggali informasi secara langsung tentang pola tabuhan instrumen Gambang pada musik Gambang Semarang kemudian mendeskripsikannya. Wawancara dilakukan dengan mewawancarai beberapa responden yaitu beberapa pemain instrumen Gambang di kota Semarang. Studi dokumen dilakukan dengan mengumpulkan informasi berupa dokumen tertulis, gambar, video. Teknik keabsahan data menggunakan triangulasi sumber, metode, dan teori. Data yang terkumpul kemudian dianalisis dalam tiga langkah; reduksi, penyajian, dan kesimpulan.

\section{ANALISIS DAN INTERPRETASI DATA}

\section{Pola Permainan Alat Musik Gambang pada musik Gambang Semarang}

Instrumen Gambang pada musik Gambang Semarang dimainkan dengan posisi duduk bersila menghadap alat musik tersebut, dimana kedua tangan pemain memegang dua buah mallet (tabuh). Tabuh yang digunakan terbuat dari kayu, pada bagian ujung tabuh ada kayu berbentuk lingkaran yang dibalut sejenis kain agar suara yang dihasilkan menjadi lembut. Cara memegang tabuh Gambang adalah jari-jari tangan kanan dan kiri melingkar/menggenggam tabuh kecuali jari telunjuk yang menempel lurus di atas tabuh.

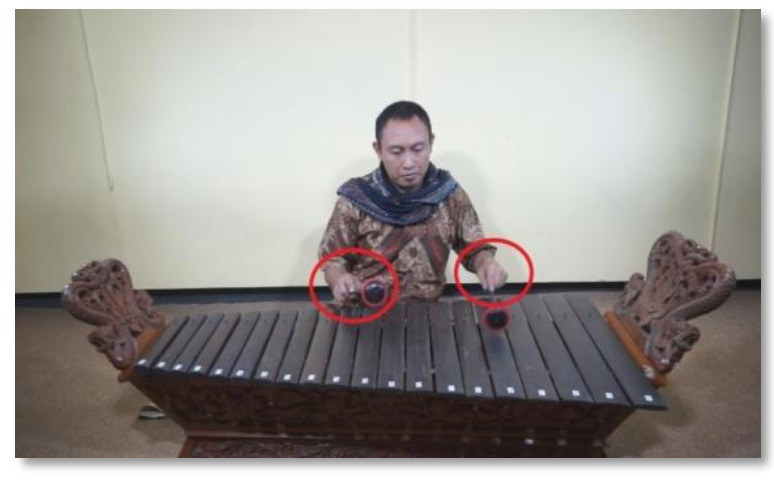

Gambar 1. Cara memainkan instrumen Gambang (Sumber: Rachman, 2020)

Teknik permainan adalah cara atau usaha untuk melakukan permainan pada alat musik dengan nada atau irama tertentu (Banoe, 2003; Suhaya et al., 2020), sedangkan pola adalah model, sistem, bentuk atau struktur. Pola irama adalah pola ritme yang diulang - ulang secara teratur sepanjang lagu sehingga membentuk satuan irama dengan nama tertentu. Suatu pola ritme yang diulang-ulang secara 
teratur dari berbagai instrumen dan dimainkan sepanjang lagu akan membentuk suatu pola irama. Pola irama ini mempunyai ciri khas tersendiri dan mempunyai nama tertentu (Banoe, 2003; Miller, 1958; Rachman \& Utomo, 2019). Jadi, bisa disimpulkan bahwa pola permainan musik adalah sebuah bentuk, struktur permainan musik dengan menggunakan nada dan atau irama tertentu yang dilakukan secara berulang dan teratur sepanjang lagu yang membentuk satuan irama dengan nama tertentu.

Pada dasarnya pola tabuhan instrumen musik Gambang Semarang belum mempunyai standar tertentu yang menjadi karakteristik musik Semarangan. Kebanyakan pola-pola tabuhan alat musik Gambang Semarang mengadopsi dari beberapa teknik/pola permainan musik Karawitan Jawa, dan juga Sunda yang kemudian dimodifikasi oleh para pemain musik Gambang Semarang. Hal ini menyebabkan adanya perbedaan pola tabuhan dari tiap pemain, hal ini justru akan menjadi gaya/style dari masing-masing pemain itu sendiri. Pada sub bab ini akan dibahas mengenai pola tabuhan dari instrumen Gambang pada musik Gambang Semarang berdasarkan data-data yang diperoleh dari beberapa nara sumber selama proses penelitian.

\section{Pola Tabuhan Gambang Gembyang Nglagu/Oktaf}

Sekaran adalah sebuah pola permainan yang sifatnya melodis dengan nilai ritmis tetap ataupun kombinasi yang cenderung mengikuti melodi lagu ataupun kembangan dari sebuah melodi lagu (Supanggah, 2009; Widodo \& Suharto, 2017). Nglagu adalah suatu bentuk pola tabuhan pengembangan dari pola tabuhan mipil, dimana pengembangannya dilakukan pada setiap akan seleh, baik pada pertengahan gatra maupun akhir gatra dengan cara mnggunakan nada-nada satu bilah lebih rendah dari nada seleh untuk dijadikan sebagai rangkaian lagu. Gembyang adalah sebuah pola tabuhan dengan membunyikan nada atas dan nada bawah notasi yang sama secara bersamaan, dimana dalam istilah musik barat pola seperti ini disebut oktaf. Misalnya membunyikan nada 1 (ji) rendah dan ji tinggi secara bersamaan. Seleh dalam karawitan adalah rasa berhenti pada sebuah kalimat lagu baik berhenti sementara atau berhenti selesai (Kurniawati, 2019; Sugimin, 2018; Supanggah, 2009; Widodo \& Suharto, 2017). Jika diterjemahkan ke dalam musik barat seleh tersebut menunjukkan wilayah akor/harmoni lagu yang sedang dimainkan, artinya jika sedang dimainkan pola tabuhan seleh do menunjukkan bahwa melodi lagu yang sedang dibawakan sedang berada pada wilayah akor do atau tingkatan akor I mayor. Sehingga bisa diambil kesimpulan bahwa Pola Tabuhan Gambang Gembyang Nglagu/Oktaf adalah sebuah pola tabuhan yang sifatnya melodis dengan nilai ritmis tetap ataupun kombinasi yang cenderung mengikuti melodi lagu ataupun kembangan dimana pengembangannya dilakukan pada setiap akan seleh dengan membunyikan nada atas dan nada bawah notasi yang sama secara bersamaan. Pola tabuhan Gambang Gembyang Nglagu/Oktaf terdiri dari lima jenis yang diberi nama seleh, yaitu seleh do, seleh re, seleh mi, seleh sol, dan seleh la. Berikut akan dibahas kelima jenis seleh tersebut di atas.

\section{Pola Tabuhan Gambang Gembyang Nglagu (oktaf) Seleh 1 (do)}

Pola tabuhan Gambang gembyang nglagu seleh 1 (do) ini dengan cara memainkan secara konsisten dua nada yang sama tetapi beda satu oktaf (nggembyang) dalam istilah barat disebut oktaf dengan nilai nada 1/8an. Nada yang rendah dipukul atau dimainkan oleh tangan kiri sedangkan nada yang tinggi dipukul/dimainkan oleh tangan kanan. Seleh 1 (do) ini menunjukkan bahwa pola ini sedang memainkan sebuah pola tabuhan pada wilayah akor tingkat I Mayor. Pola tabuh dasar sekaran tabuhan Gambang gembyang nglagu seleh do ini secara lengkap biasanya membutuhkan dua bar pada setiap polanya yaitu dua kali empat ketukan karena lagulagu musik Gambang Semarang kebanyakan memiliki birama 4/4, akan tetapi ini tergantung dari ritme akor yang dimainkan. Jika akor yang sedang dimainkan hanya memiliki panjang satu bar, maka pola tabuhan Gambang yang dimainkan hanya separuhnya saja (satu bar), jika akor yang sedang dimainkan memiliki panjang dua bar, maka pola tabuhan yang dimainkan bisa penuh yaitu dua bar.

Pola tabuhan Gambang gembyang nglagu seleh 1 (do) bukan memainkan nada 1 (do) saja, tetapi dalam satu pola memainkan beberapa rangkaian nada sebelahnya yang sifatnya melangkah naik (ascending) dan kemudian melangkah turun (descending) untuk kembali lagi ke nada seleh-nya yaitu nada 1 (do). Rangkaian nada-nada yang bisa digunakan pada pola tabuh seleh 1 (do) adalah 2 (re), 3 (mi), 5 (sol), dan 6 (la). Masing-masing rangkaian nada-nada tersebut dimainkan dengan nilai nada 1/8an. Pola tabuhan Gambang gembyang nglagu seleh 1 (do) bisa dilihat pada partitur di bawah ini: 


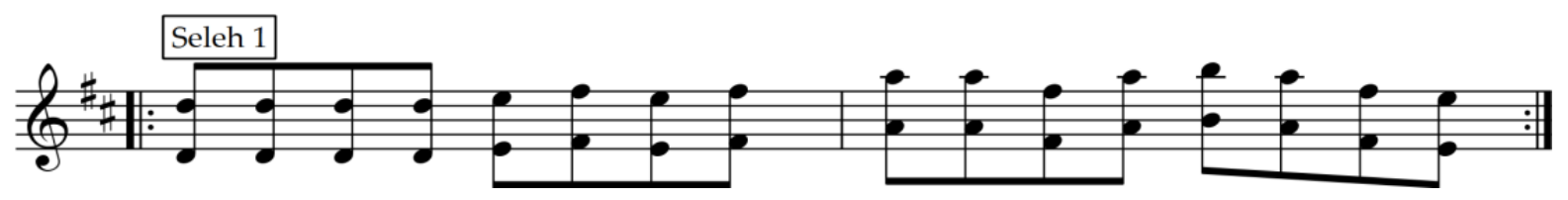

Partitur 1.Pola tabuhan Gambang Gembyang Nglagu (oktaf) Seleh 1 (do)

(Sumber: Rachman, 2020)

Jika kita lihat pada Partitur 1 di atas, Pola tabuhan Gambang gembyang nglagu seleh 1 (do) pada birama pertama memainkan notasi 1 (do) pada dua ketukan pertama, kemudian dilanjutkan notasi 2 (re) dan 3 (mi) pada ketukan ketiga, kembali ke notasi 2 (re) dan 3 (mi) lagi diketukan keempat, dimana masing-masing menggunakan nilai notasi 1/8an. Perlu dicatat bahwa pada ketukan pertama memainkan notasi 1 (do) dengan tujuan untuk menunjukkan wilayah akor yang sedang dimainkan, yaitu akor I yang tersusun dari notasi 1 (do), 3 (mi), dan 5 (sol). Jika pada ketukan pertama/ ketukan berat/vorhalt menggunakan notasi 3 (mi) atau 5 (sol), dikhawatirkan akan menyebabkan bias wilayah akor yang sedang dimainkan.

Kemudian pada birama kedua memainkan notasi sol 5 (sol) pada ketukan pertama yang dilanjutkan notasi 3 (mi) dan 5 (sol) pada ketukan kedua, sedangkan pada ketukan ketiga memainkan notasi 6 (la) dan 5 (sol) dan dilanjutkan dengan notasi 3 (mi) dan 2 (re) pada ketukan keempat, masing-masing juga memainkan notasi 1/8an (seperdelapanan). Akan tetapi perlu diingat sekali lagi bahwa pola ini tergantung interpretasi dari sang pemain itu sendiri, karena berbeda pemain maka akan berbeda juga rangkaian nada-nada yang akan digunakan.

\section{Pola Tabuhan Gambang Gembyang Nglagu (oktaf) Seleh 2 (re)}

Pola tabuhan Gambang gembyang nglagu seleh 2 (re) ini dengan cara memainkan secara konsisten dua nada yang sama tetapi beda satu oktaf (nggembyang) dalam istilah barat disebut oktaf dengan nilai nada 1/8an. Nada yang rendah dipukul atau dimainkan oleh tangan kiri sedangkan nada yang tinggi dipukul/dimainkan oleh tangan kanan. Seleh 2 (re) ini menunjukkan bahwa pola ini sedang memainkan sebuah pola tabuhan pada wilayah akor tingkat II yang biasanya cenderung Minor. Pola tabuh dasar sekaran tabuhan Gambang gembyang nglagu seleh 2 (re) ini secara lengkap biasanya juga membutuhkan dua bar pada setiap polanya yaitu dua kali empat ketukan karena lagu-lagu musik Gambang Semarang kebanyakan memiliki birama 4/4, akan tetapi ini tergantung dari ritme akor yang dimainkan. Jika akor yang sedang dimainkan hanya memiliki panjang satu bar, maka pola tabuhan Gambang yang dimainkan hanya separuhnya saja (satu bar), jika akor yang sedang dimainkan memiliki panjang dua bar, maka pola tabuhan yang dimainkan bisa penuh yaitu dua bar.

Pola tabuhan Gambang gembyang nglagu seleh 2 (re) bukan memainkan nada 2 (re) saja, tetapi dalam satu pola memainkan beberapa rangkaian nada sebelahnya yang sifatnya melangkah naik (ascending) dan kemudian melangkah turun (descending) untuk kembali lagi ke nada seleh-nya yaitu nada 2 (re). Rangkaian nada-nada yang bisa digunakan pada pola tabuh seleh 2 (re) adalah 2 (re), 3 (mi), 5 (sol), dan 6 (la) dan 1 (do) tinggi. Masingmasing rangkaian nada-nada tersebut dimainkan dengan nilai nada 1/8an. Pola tabuhan Gambang gembyang nglagu seleh 2 (re) bisa dilihat pada partitur di bawah ini:

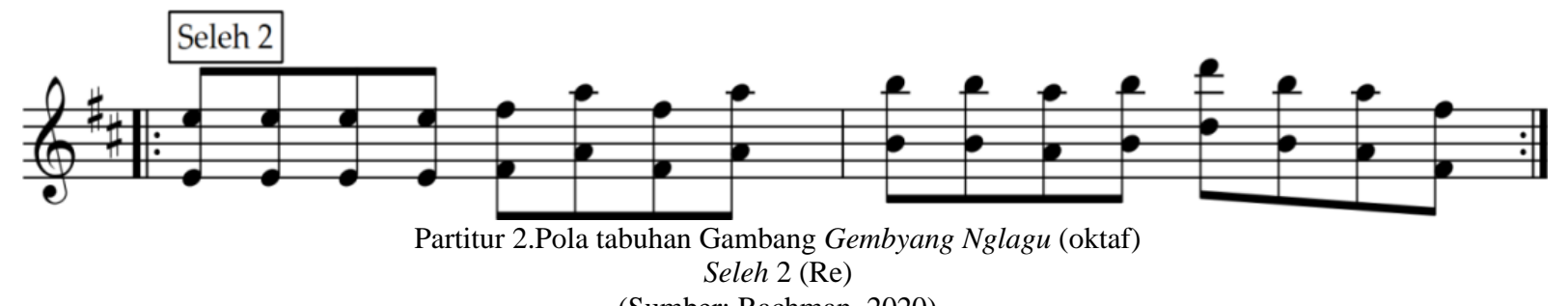

(Sumber: Rachman, 2020)

Jika kita lihat pada Partitur 2 di atas, Pola tabuhan Gambang gembyang nglagu seleh 2 (re) pada birama pertama memainkan notasi 2 (re) pada dua ketukan pertama, kemudian dilanjutkan notasi 3 (mi) dan 5 (sol) pada ketukan ketiga, kembali ke notasi 3 (mi) dan 5 (sol) lagi diketukan keempat, dimana masingmasing menggunakan nilai notasi 1/8an. Kemudian pada birama kedua memainkan notasi sol 6 (la) pada ketukan pertama yang dilanjutkan notasi 5 (sol) dan 6 (la) pada ketukan kedua, sedangkan pada ketukan ketiga memainkan notasi 1 (do) tinggi dan 6 (la) dan dilanjutkan dengan notasi 5 (sol) dan 3 (mi) pada ketukan keempat, masing-masing juga memainkan notasi 1/8an (seperdelapanan). 


\section{Pola Tabuhan Gambang Gembyang Nglagu (oktaf) Seleh 3 (Mi)}

Pola tabuhan Gambang gembyang nglagu seleh 3 (mi) ini dengan cara memainkan secara konsisten dua nada yang sama tetapi beda satu oktaf (nggembyang) dalam istilah barat disebut oktaf dengan nilai nada 1/8an. Nada yang rendah dipukul atau dimainkan oleh tangan kiri sedangkan nada yang tinggi dipukul/dimainkan oleh tangan kanan. Seleh 3 (mi) ini menunjukkan bahwa pola ini sedang memainkan sebuah pola tabuhan pada wilayah akor tingkat III yang biasanya cenderung Minor. Pola tabuh dasar sekaran tabuhan Gambang gembyang nglagu seleh 3 (mi) ini secara lengkap biasanya juga membutuhkan dua bar pada setiap polanya yaitu dua kali empat ketukan karena lagu-lagu musik Gambang Semarang kebanyakan memiliki birama 4/4, akan tetapi ini tergantung dari ritme akor yang dimainkan. Jika akor yang sedang dimainkan hanya memiliki panjang satu bar, maka pola tabuhan Gambang yang dimainkan hanya separuhnya saja (satu bar), jika akor yang sedang dimainkan memiliki panjang dua bar, maka pola tabuhan yang dimainkan bisa penuh yaitu dua bar.

Pola tabuhan Gambang gembyang nglagu seleh 3 (mi) bukan memainkan nada 3 (mi) saja, tetapi dalam satu pola memainkan beberapa rangkaian nada sebelahnya yang sifatnya melangkah naik (ascending) dan kemudian melangkah turun (descending) untuk kembali lagi ke nada seleh-nya yaitu nada 3 (mi). Rangkaian nada-nada yang bisa digunakan pada pola tabuh seleh 3 (mi) adalah 3 (mi), 5 (sol), 6 (la), 1 (do), dan 2 (re) tinggi. Masingmasing rangkaian nada-nada tersebut dimainkan dengan nilai nada 1/8an. Pola tabuhan Gambang gembyang nglagu seleh 3 (mi)) bisa dilihat pada partitur di bawah ini:

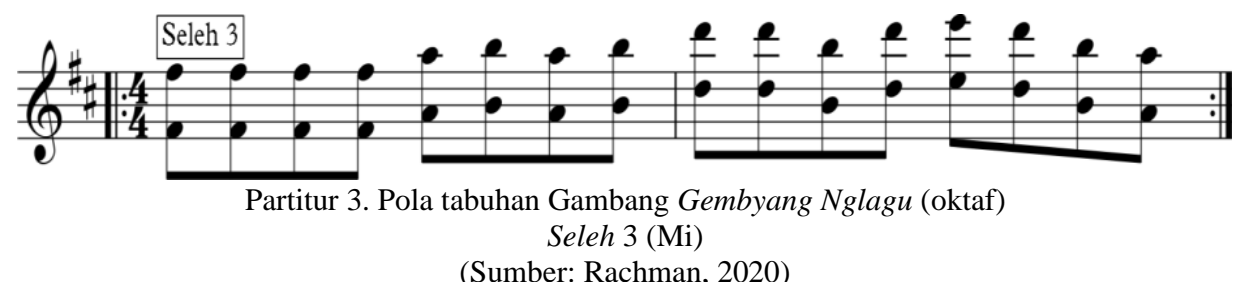

Jika kita lihat pada Partitur 3 di atas, Pola tabuhan Gambang gembyang nglagu seleh 3 (mi) pada birama pertama memainkan notasi 3 (mi) pada dua ketukan pertama, kemudian dilanjutkan notasi 5 (sol) dan 6 (la) pada ketukan ketiga, kembali ke notasi 5 (sol) dan 6 (la) lagi diketukan keempat, dimana masing-masing menggunakan nilai notasi 1/8an.

Kemudian pada birama kedua memainkan notasi 1 (do) tinggi pada ketukan pertama yang dilanjutkan notasi 6 (la) dan 1 (do) tinggi pada ketukan kedua, sedangkan pada ketukan ketiga memainkan notasi 2 (re) tinggi dan 1 (do) tinggi dan dilanjutkan dengan notasi 6 (la) dan 5 (sol) pada ketukan keempat, masing-masing juga memainkan notasi 1/8an (seperdelapanan).

\section{Pola Tabuhan Gambang Gembyang Nglagu (oktaf) Seleh 5 (Sol)}

Pola tabuhan Gambang gembyang nglagu seleh 5 (sol) ini dengan cara memainkan secara konsisten dua nada yang sama tetapi beda satu oktaf (nggembyang) dalam istilah barat disebut oktaf dengan nilai nada 1/8an. Nada yang rendah dipukul atau dimainkan oleh tangan kiri sedangkan nada yang tinggi dipukul/dimainkan oleh tangan kanan.
Seleh 5 (sol) ini menunjukkan bahwa pola ini sedang memainkan sebuah pola tabuhan pada wilayah akor tingkat V Mayor. Pola tabuh dasar sekaran tabuhan Gambang gembyang nglagu seleh 5 (sol) ini secara lengkap biasanya juga membutuhkan dua bar pada setiap polanya yaitu dua kali empat ketukan karena lagu-lagu musik Gambang Semarang kebanyakan memiliki birama 4/4, akan tetapi ini tergantung dari ritme akor yang dimainkan. Jika akor yang sedang dimainkan hanya memiliki panjang satu bar, maka pola tabuhan Gambang yang dimainkan hanya separuhnya saja (satu bar), jika akor yang sedang dimainkan memiliki panjang dua bar, maka pola tabuhan yang dimainkan bisa penuh yaitu dua bar.

Pola tabuhan Gambang gembyang nglagu seleh 5 (sol) bukan memainkan nada 5 (sol) saja, tetapi dalam satu pola memainkan beberapa rangkaian nada sebelahnya yang sifatnya melangkah naik (ascending) dan kemudian melangkah turun (descending) untuk kembali lagi ke nada seleh-nya yaitu nada 5 (sol). Rangkaian nada-nada yang bisa digunakan pada pola tabuh seleh 5 (sol) adalah 5 (sol), 6 (la), 1 (do), 2 (re), dan 3 (mi). Masingmasing rangkaian nada-nada tersebut dimainkan dengan nilai nada 1/8an. Pola tabuhan Gambang gembyang nglagu seleh 5 (sol) bisa dilihat pada 
partitur di bawah ini:

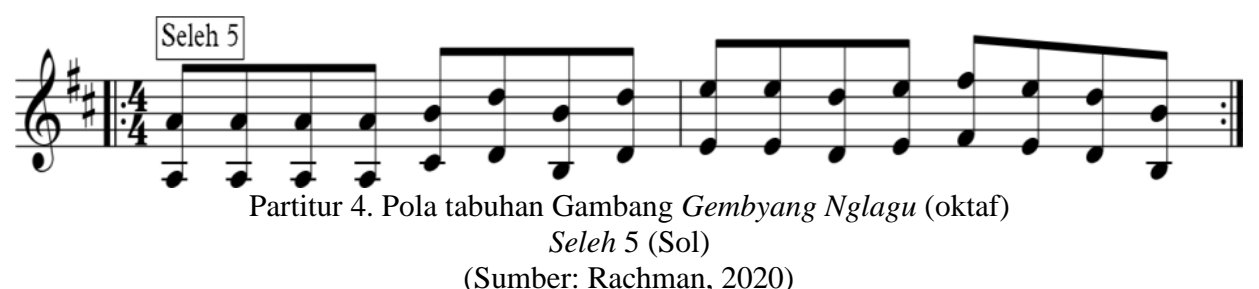

Jika kita lihat pada Partitur 4 di atas, Pola tabuhan Gambang gembyang nglagu seleh 5 (sol) pada birama pertama memainkan notasi 5 (sol) pada dua ketukan pertama, kemudian dilanjutkan notasi 6 (la) dan 1 (do) pada ketukan ketiga, kembali ke notasi 6 (la) dan 1 (do) lagi diketukan keempat, dimana masing-masing menggunakan nilai notasi 1/8an.

Kemudian pada birama kedua memainkan notasi 2 (re) tinggi pada ketukan pertama yang dilanjutkan notasi 1 (do) dan 2 (re) pada ketukan kedua, sedangkan pada ketukan ketiga memainkan notasi 3 (mi) dan 2 (re) dan dilanjutkan dengan notasi 1 (do) dan 6 (la) pada ketukan keempat, masing-masing juga memainkan notasi 1/8an (seperdelapanan).

\section{Pola Tabuhan Gambang Gembyang Nglagu (oktaf) Seleh 6 (La)}

Pola tabuhan Gambang gembyang nglagu seleh 6 (la) ini dengan cara memainkan secara konsisten dua nada yang sama tetapi beda satu oktaf (nggembyang) dalam istilah barat disebut oktaf dengan nilai nada 1/8an. Nada yang rendah dipukul atau dimainkan oleh tangan kiri sedangkan nada yang tinggi dipukul/dimainkan oleh tangan kanan. Seleh 6 (la) ini menunjukkan bahwa pola ini sedang memainkan sebuah pola tabuhan pada wilayah akor tingkat VI yang biasanya cenderung Minor. Pola tabuh dasar sekaran tabuhan Gambang gembyang nglagu seleh 6 (la) ini secara lengkap biasanya juga membutuhkan dua bar pada setiap polanya yaitu dua kali empat ketukan karena lagu-lagu musik Gambang Semarang kebanyakan memiliki birama 4/4, akan tetapi ini tergantung dari ritme akor yang dimainkan. Jika akor yang sedang dimainkan hanya memiliki panjang satu bar, maka pola tabuhan Gambang yang dimainkan hanya separuhnya saja (satu bar), jika akor yang sedang dimainkan memiliki panjang dua bar, maka pola tabuhan yang dimainkan bisa penuh yaitu dua bar.

Pola tabuhan Gambang gembyang nglagu seleh 6 (la) bukan memainkan nada 6 (la) saja, tetapi dalam satu pola memainkan beberapa rangkaian nada sebelahnya yang sifatnya melangkah naik (ascending) dan kemudian melangkah turun (descending) untuk kembali lagi ke nada seleh-nya yaitu nada 6 (la). Rangkaian nada-nada yang bisa digunakan pada pola tabuh seleh 6 (la) adalah 6 (la), 1 (do), 2 (re), 3 (mi), 5 (sol). Masing-masing rangkaian nada-nada tersebut dimainkan dengan nilai nada 1/8an. Pola tabuhan Gambang gembyang nglagu seleh 6 (la) bisa dilihat pada partitur di bawah ini:

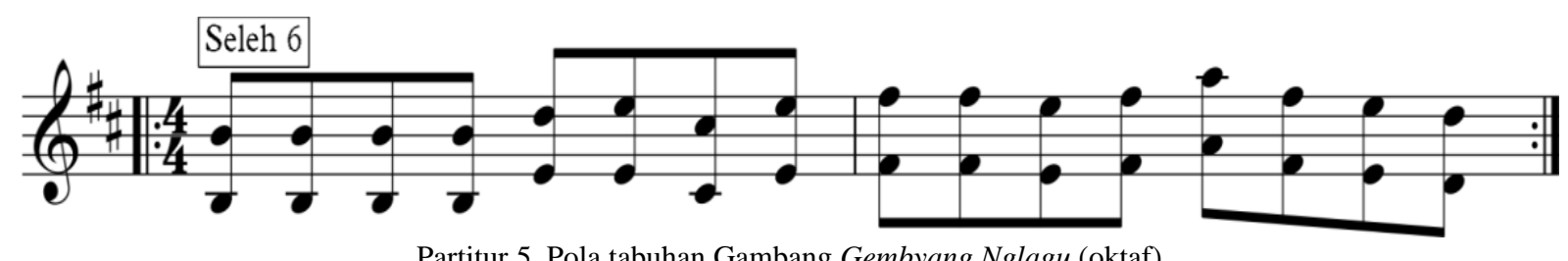

Partitur 5. Pola tabuhan Gambang Gembyang Nglagu (oktaf) Seleh 6 (La)

(Sumber: Rachman, 2020)

Jika kita lihat pada Partitur 5 di atas, pola tabuhan Gambang gembyang nglagu seleh 6 (la) pada birama pertama memainkan notasi 6 (la) pada dua ketukan pertama, kemudian dilanjutkan notasi 1 (do) dan 2 (re) pada ketukan ketiga, kembali ke notasi 1 (do) dan 2 (re) lagi diketukan keempat, dimana masingmasing menggunakan nilai notasi 1/8an.

Pada birama kedua memainkan notasi 3 (mi) tinggi pada ketukan pertama yang dilanjutkan notasi 2 (re) dan 3 (mi) pada ketukan kedua, sedangkan pada ketukan ketiga memainkan notasi 5 (sol) dan 3 (mi) dan dilanjutkan dengan notasi 2 (re) dan 1 (do) pada ketukan keempat, masing-masing juga memainkan notasi 1/8an (seperdelapanan).

\section{Pola Tabuhan Gambang Garap Cengkok Ajeg (Monoton)}

Garap adalah mengolah unsur-usur musikal dan kultural gending mengikuti kaidah garap yang berlaku, karakter, dan fungsi penyajiannya sehingga 
terbentuk jalinan komposisi bunyi karawitan indah. Cengkok merupakan salah satu istilah yang paling sering digunakan untuk menyebut pola tabuhan dalam karawitan. Cengkok adalah konfigurasi nada dan atau ritme yang telah ditentukan panjangnya, biasanya sepanjang satu gatra, atau kelipatan ganda, atau paruhannya, atau sepanjang satu kalimat lagu pendek (Haris et al., 2017; Supanggah, 2009; Widodo \& Suharto, 2017). Jadi bisa disimpulkan bahwa pola dasar tabuhan Gambang garap cengkok ajeg adalah sebuah pola tabuhan yang mengolah unsur-unsur musikal seperti konfigurasi nada dan atau ritme dengan panjang tertentu yang sifatnya tetap atau diulang-ulang sehingga terbentuk jalinan komposisi yang indah.

Sangat berbeda dengan teknik memainkan pola tabuhan Gambang gembyang nglagu, jika pada Pola tabuhan gembyang nglagu tangan kanan dan kiri memainkan ritmis yang sama dan nada yang sama akan tetapi berbeda oktaf, pada pola dasar tabuhan Gambang garap cengkok ajeg tangan kanan dan kiri memainkan nada dan ritmis yang berbeda. Pola dasar tabuhan Gambang garap cengkok ajeg hanya dibentuk dalam satu bar saja. Tangan kanan memainkan ritmis setengah sabetan yaitu not $1 / 8$ an (seperdelapanan) yang konstan dengan rincian pada ketukan kesatu dan ketiga dimulai dengan tanda istirahat 1/8an (seperdelapanan) kemudian diikuti not 1/8an, pada ketukan kedua dan keempat memainkan dua notasi 1/8an. Sedangkan tangan kiri ketukan pertama memainkan not 1/2an kemudian diikuti not $1 / 16$ an pada ketukan berikutnya.

Bisa disebut bahwa pada pola dasar garap cengkok ajeg ini seperti memainkan teknik kothekan, dimana tangan kanan dan kiri memainkan sebuah pola ritmis yang saling mengisi satu sama lain. Kothekan adalah teknik menabuh secara bergantian yang saling mengisi antara dua ricikan (instrumen) atau lebih yang sejenis dengan jarak tabuhan setengah sabetan (Supanggah, 2009). Pola ini juga bisa disebut dengan interlocking pattern, seperti yang dikatakan oleh (Wimbrayardi \& Parmadi, 2021) yaitu sebuah pola pukulan yang saling saut menyaut antara dua buah instrumen atau lebih. Hal yang perlu digarisbawahi pada teknik kothekan adalah bahwa teknik ini dimainkan oleh dua intrumen atau lebih yang artinya juga akan ada dua pemain atau lebih, akan tetapi pada konteks pola tabuhan cengkok garap ajeg pada instrumen Gambang ini dimainkan oleh satu orang dan satu ricikan saja, sehingga teknik ini memiliki tingkat kesulitan yang sangat tinggi, diperlukan kelincahan dan koordinasi antara tangan kanan dan kiri si pemain. Oleh karena itu penulisannya ke dalam notasi musik menjadi dua tingkat paranada yaitu atas dan bawah seperti grand stave pada musik barat akan tetapi dua tingkat paranada tersebut sama-sama menggunakan kunci $\mathrm{G}$, sedangkan pada grand stave (penulisan partitur untuk alat musik Piano) menggunakan kunci $G$ untuk paranada atas dan kunci $\mathrm{F}$ untuk paranada bawah. Pada penulisan pola tabuhan cengkok garap ajeg paranada atas merupakan pola ritmis/tabuhan yang dimainkan tangan kanan, sedangkan paranada bawah merupakan pola ritmis/tabuhan yang dimainkan tangan kiri. Pola dasar tabuhan Gambang garap cengkok ajeg juga terdiri dari lima jenis berdasarkan seleh-nya, yaitu seleh do, seleh re, seleh mi, seleh sol, dan seleh la. Berikut akan dibahas kelima jenis seleh tersebut di atas.

\section{Pola Tabuhan Gambang Garap Cengkok Ajeg (monoton) Seleh 1 (Do)}

Pola tabuhan Gambang garap cengkok ajeg seleh 1 (do) menunjukkan bahwa pola ini sedang memainkan sebuah pola tabuhan pada wilayah akor tingkat I Mayor. Pola dasar tabuhan Gambang garap cengkok ajeg seleh 1 (do) secara lengkap membutuhkan satu bar saja pada setiap polanya. Pola tabuhannya adalah dengan cara tangan kanan secara konsisten memainkan dua notasi yaitu 5 ( $\mathrm{sol}$ ) dan 6 (la) masing-masing bernilai 1/8an. Pada ketukan pertama diawali tanda istirahat 1/8an kemudian diikuti notasi 1/8an 5 (sol), ketukan kedua diawali dengan notasi 1/8an 6 (la) kemudian diikuti notasi 1/8an 5 (sol), sama seperti ketukan pertama, ketukan ketiga diawali dengan tanda istirahat 1/8an yang kemudian diikuti notasi 5 (sol) dengan nilai not 1/8an, kemudian ketukan keempat memainkan notasi 1/8an 6 (la) dan diikuti notasi 1/8an 5 (sol).

Pola tabuhan yang dimainkan tangan kiri adalah memainkan ritmis yang terdiri dari dua notasi yaitu 1 (do) dan 5 (sol), dimana notasi 1 (do) sebagai nada selehnya (tonika), sedangkan notasi 5 (sol) sebagai pasangannya (kwint). Notasi 1 (do) dimainkan dengan nilai not $1 / 2$ an pada ketukan pertama, kemudian pada ketukan kedua memainkan dua notasi 5 (sol) dengan nilai nada 1/16an yang dilanjutkan tanda istirahat dan notasi 5 (sol) dengan nilai $1 / 6$ an dan pada ketukan keempat memainkan notasi 5 (sol) dengan nilai 1/6an diikuti tanda istirahat 1/16an dan notasi 5 (sol) 1/8an.

Pola dasar tabuhan Gambang garap cengkok ajeg seleh 1 (do) bisa dilihat pada partitur di bawah ini: 


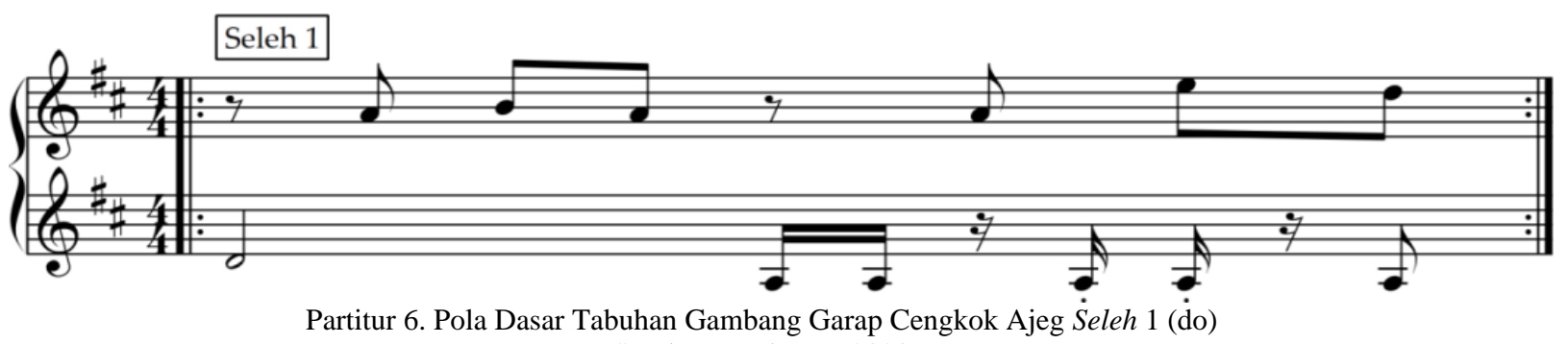

(Sumber: Rachman, 2020)

Pola Tabuhan Gambang Garap Cengkok Ajek (monoton) Seleh 2 (Re)

Pola dasar tabuhan Gambang garap cengkok ajeg seleh 2 (re) menunjukkan bahwa pola ini sedang memainkan sebuah pola tabuhan pada wilayah akor tingkat II minor. Pola dasar tabuhan Gambang garap cengkok ajeg seleh 2 (re) secara lengkap membutuhkan satu bar saja pada setiap polanya. Pola tabuhannya adalah dengan cara tangan kanan secara konsisten memainkan dua notasi yaitu 6 (la) dan 1 (do) masing-masing bernilai 1/8an. Pada ketukan pertama diawali tanda istirahat 1/8an kemudian diikuti notasi 1/8an 6 (la), ketukan kedua diawali dengan notasi 1/8an 1 (do) kemudian diikuti notasi 1/8an 6 (la), sama seperti ketukan pertama, ketukan ketiga diawali dengan tanda istirahat 1/8an yang kemudian diikuti notasi 6 (la) dengan nilai not 1/8an, kemudian ketukan keempat memainkan notasi 1/8an 1 (do) dan diikuti notasi 1/8an6 (la).

Pola tabuhan yang dimainkan tangan kiri adalah memainkan ritmis yang terdiri dari dua notasi yaitu 2 (re) dan 6 (la), dimana notasi 2 (re) sebagai nada seleh-nya, sedangkan notasi 6 (la) sebagai pasangannya. Hal ini mengadopsi kaedah musik barat. Notasi 2 (re) dimainkan dengan nilai not 1/2an pada ketukan pertama, kemudian pada ketukan kedua memainkan dua notasi 6 (la) dengan nilai nada $1 / 16$ an yang dilanjutkan tanda istirahat dan notasi 6 (la) dengan nilai 1/6an dan pada ketukan keempat memainkan notasi 6 (la) dengan nilai $1 / 6$ an diikuti tanda istirahat $1 / 16$ an dan notasi 6 (la) $1 / 8$ an.

Pola dasar tabuhan Gambang garap cengkok ajeg seleh 2 (re) bisa dilihat pada partitur di bawah ini:

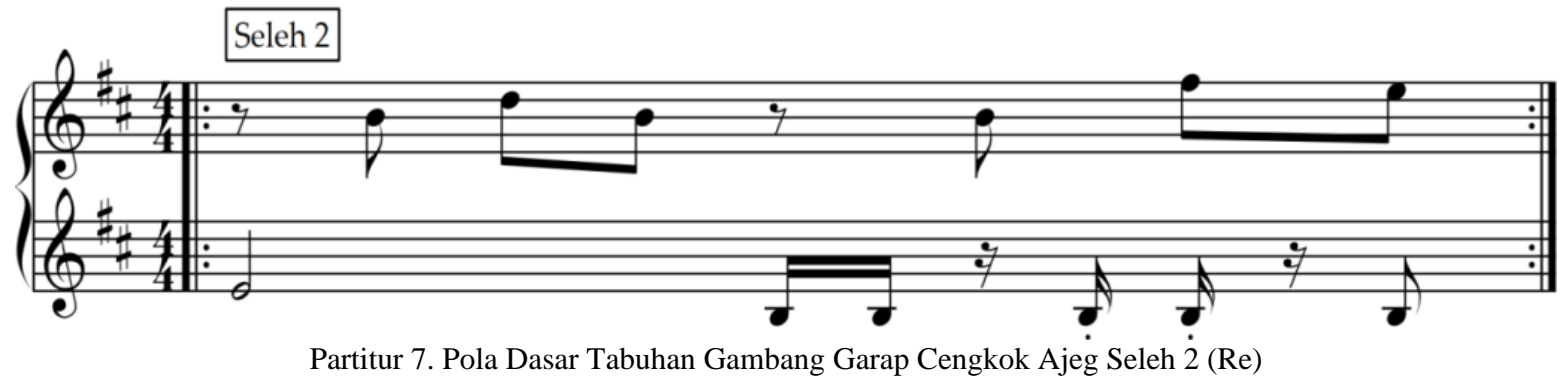

(Sumber: Rachman, 2020)

Pola Tabuhan Gambang Garap Cengkok Ajek (monoton) Seleh 3 (Mi)

Pola dasar tabuhan Gambang garap cengkok ajeg seleh 3 (mi) menunjukkan bahwa pola ini sedang memainkan sebuah pola tabuhan pada wilayah akor tingkat III minor. Pola dasar tabuhan Gambang garap cengkok ajeg seleh 3 (mi) secara lengkap membutuhkan satu bar saja pada setiap polanya. Pola tabuhannya adalah dengan cara tangan kanan secara konsisten memainkan dua notasi yaitu 1 (do) dan 2 (re) masing-masing bernilai 1/8an. Pada ketukan pertama diawali tanda istirahat 1/8an kemudian diikuti notasi 1/8an 1 (do), ketukan kedua diawali dengan notasi 1/8an 2 (re) kemudian diikuti notasi 1/8an 1 (do), sama seperti ketukan pertama, ketukan ketiga diawali dengan tanda istirahat 1/8an yang kemudian diikuti notasi 1 (do) dengan nilai not 1/8an, kemudian ketukan keempat memainkan notasi 1/8an 2 (re) dan diikuti notasi 1/8an 1 (do).

Pola tabuhan yang dimainkan tangan kiri adalah memainkan ritmis yang terdiri dari dua notasi yaitu 3 (mi) dan 1 (do), dimana notasi 3 (mi) sebagai nada selehnya, sedangkan notasi 1 (do) sebagai pasangannya. Hal ini mengadopsi kaedah musik barat. Notasi 3 (mi) dimainkan dengan nilai not 1/2an pada ketukan pertama, kemudian pada ketukan kedua memainkan dua notasi 1 (do) dengan nilai nada 1/16an yang dilanjutkan tanda istirahat dan notasi 1 (do) dengan nilai 1/6an dan pada ketukan keempat memainkan notasi 1 (do) dengan nilai $1 / 6$ an diikuti tanda istirahat $1 / 16$ an dan notasi 1 (do) $1 / 8$ an. 


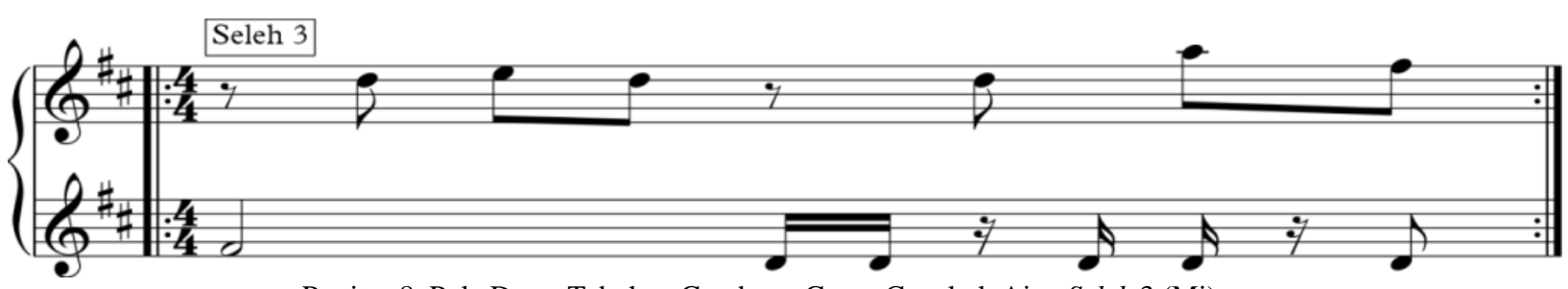

Partitur 8. Pola Dasar Tabuhan Gambang Garap Cengkok Ajeg Seleh 3 (Mi) (Sumber: Rachman, 2020)

\section{Pola Tabuhan Gambang Garap Cengkok Ajek (monoton) Seleh 5 (Sol)}

Pola tabuhan Gambang garap cengkok ajeg seleh 5 (sol) menunjukkan bahwa pola ini sedang memainkan sebuah pola tabuhan pada wilayah akor tingkat V mayor. Pola dasar tabuhan Gambang garap cengkok ajeg seleh 5 (sol) secara lengkap membutuhkan satu bar saja pada setiap polanya. Pola tabuhannya adalah dengan cara tangan kanan secara konsisten memainkan dua notasi yaitu 2 (re) dan 3 (mi) masing-masing bernilai 1/8an. Pada ketukan pertama diawali tanda istirahat 1/8an kemudian diikuti notasi 1/8an 2 (re), ketukan kedua diawali dengan notasi 1/8an 3 (mi) kemudian diikuti notasi 1/8an 2 (re), sama seperti ketukan pertama, ketukan ketiga diawali dengan tanda istirahat 1/8an yang kemudian diikuti notasi 2 (re) dengan nilai not 1/8an, kemudian ketukan keempat memainkan notasi 1/8an 3 (mi) dan diikuti notasi 1/8an 2 (re).

Pola tabuhan yang dimainkan tangan kiri adalah memainkan ritmis yang terdiri dari dua notasi yaitu 5 (sol) dan 2 (re), dimana notasi 5 (sol) sebagai nada selehnya, sedangkan notasi 2 (re) merupakan pasangannya. Hal ini mengadopsi kaedah musik barat. Notasi 5 (sol) dimainkan dengan nilai not 1/2an pada ketukan pertama, kemudian pada ketukan kedua memainkan dua notasi 2 (re) dengan nilai nada 1/16an yang dilanjutkan tanda istirahat dan notasi 2 (re) dengan nilai 1/6an dan pada ketukan keempat memainkan notasi 2 (re) dengan nilai $1 / 6$ an diikuti tanda istirahat 1/16an dan notasi 2 (re) $1 / 8$ an.

Pola dasar tabuhan Gambang garap cengkok ajeg seleh 5 (sol) bisa dilihat pada partitur di bawah ini:

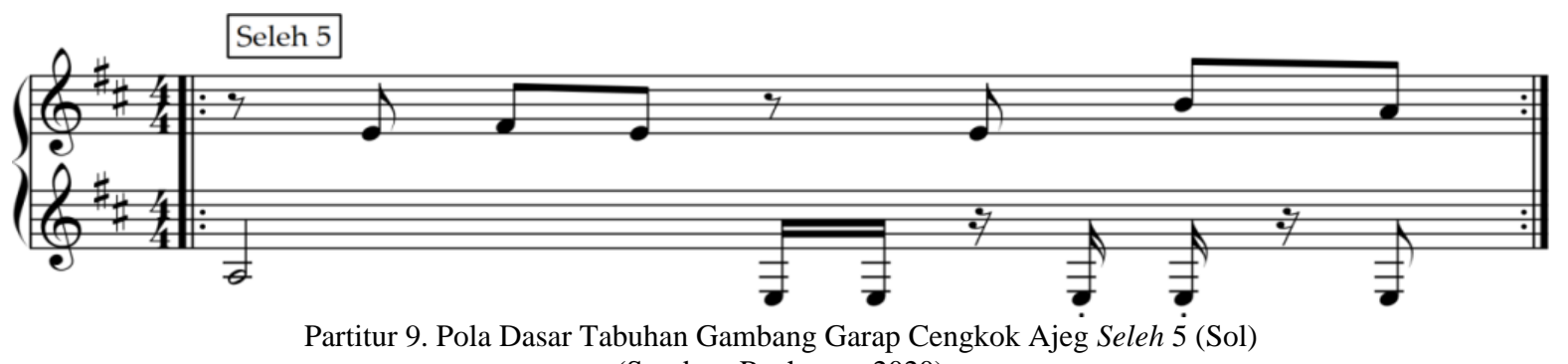

(Sumber: Rachman, 2020)

\section{Pola Tabuhan Gambang Garap Cengkok Ajeg (monoton) Seleh 6 (La)}

Pola tabuhan Gambang garap cengkok ajeg seleh 6 (la) menunjukkan bahwa pola ini sedang memainkan sebuah pola tabuhan pada wilayah akor tingkat VI minor. Pola dasar tabuhan Gambang garap cengkok ajeg seleh 6 (la) secara lengkap membutuhkan satu bar saja pada setiap polanya. Pola tabuhannya adalah dengan cara tangan kanan secara konsisten memainkan dua notasi yaitu 3 (mi) dan 5 (sol) masing-masing bernilai 1/8an. Pada ketukan pertama diawali tanda istirahat 1/8an kemudian diikuti notasi 1/8an 3 (mi), ketukan kedua diawali dengan notasi 1/8an 5 (sol) kemudian diikuti notasi 1/8an 3 (mi), sama seperti ketukan pertama, ketukan ketiga diawali dengan tanda istirahat 1/8an yang kemudian diikuti notasi 3 (mi) dengan nilai not 1/8an, kemudian ketukan keempat memainkan notasi 1/8an 5 (sol) dan diikuti notasi 1/8an 3 (mi). Pola tabuhan yang dimainkan tangan kiri adalah memainkan ritmis yang terdiri dari dua notasi yaitu 6 (la) dan 3 (mi), dimana notasi 6 (la) sebagai nada selehnya, sedangkan notasi 3 (mi) merupakan pasangannya. Hal ini mengadopsi kaedah musik barat. Notasi 6 (la) dimainkan dengan nilai not 1/2an pada ketukan pertama, kemudian pada ketukan kedua memainkan dua notasi 3 (mi) dengan nilai nada $1 / 16$ an yang dilanjutkan tanda istirahat dan notasi 3 (mi) dengan nilai 1/6an dan pada ketukan keempat memainkan notasi 3 (mi) dengan nilai $1 / 6$ an diikuti tanda istirahat $1 / 16 a n$ dan notasi 3 (mi) 1/8an. 


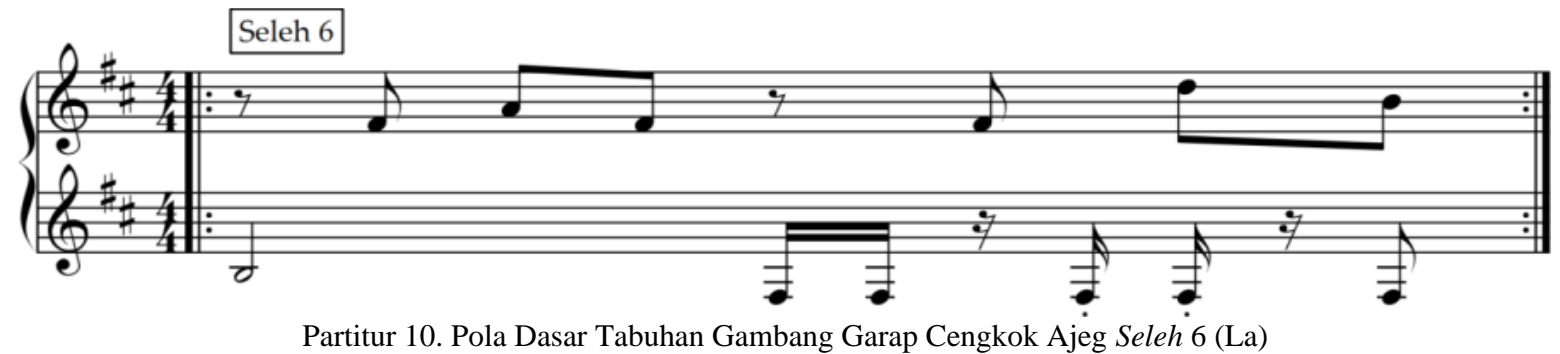
(Sumber: Rachman, 2020)

\section{SIMPULAN}

Berdasarkan hasil penelitian dan pembahasan, dapat disimpulkan bahwa ragam pola tabuhan instrumen Gambang pada musik Gambang Semarang terdiri dari dua pola yaitu pola tabuhan sekaran gembyang nglagu dan pola tabuhan garap cengkok ajeg. Pola tabuhan Sekaran gembyang nglagu memainkan rangkaian nada-nada dengan nilai nada 1/8an secara konstan, mempunyai pola pukulan berpasangan oktaf, serta memainkan rangkaian nada-nada yang mengikuti melodi lagu utama. Karena mengikuti melodi lagu utama maka pola tabuhan ini memiliki enam seleh yaitu gembyang nglagu seleh do, seleh re, seleh mi, seleh sol, dan seleh la. Pola tabuhan garap cengkok ajeg memainkan pola ritmis yang berbeda antara tangan kiri dan kanan dimana kedua tangan ini saling mengisi satu sama lain (interlocking pattern) yang menjadi satu kesatuan pola irama. Pola tabuhan garap cengkok ajeg juga mengikuti melodi lagu utama yang menyebabkan pola ini terbagi menjadi enam seleh yaitu pola tabuhan garap cengkok ajeg seleh do, seleh re, seleh mi, seleh sol, dan seleh la.

\section{DAFTAR RUJUKAN}

Amanah, S. (2009). Tradisi dalam Hidup Etnik Arab di Kampung Melayu Kelurahan Dadapsari Semarang. Sabda, 4(1).

Ardana, I. K. (2009). Fungsi Karawitan Bali di Yogyakarta: Sebuah Tinjauan Kontekstual. Mudra Journal of Art and Culture, 24(1), 1-2.

Banoe, P. (2003). Kamus Musik. Kanisius Press. Carey, P. (1985). Orang Jawa dan Masyarakat Cina (1755-1825). Pustaka Azet.

Graaf, H. J. (1998). Cina Muslim di Jawa Abad XV dan XVI antara Historisitas dan Mitos. Tiara Wacana.
Graaf, H. J., \& Pigeaud, T. (1989). Kerajaankerajaan Islam di Jawa: Peralihan dari Majapahit ke Mataram. Grafiti.

Haris, A. S., Supanggah, R., Sukerta, P. M., \& Sunarto, B. (2017). " BE YOURSELF" ( The Creation of a Music Composition ). Panggung, 27(4), 308-318.

Kurniawati, R. (2019). Bentuk dan Fungsi Galong dalam Pakeliran Tradisi Ngayogyakarta. Institut Seni Indonesia Yogyakarta.

Miller, H. M. (1958). Introduction to Music: A Guide to Good Listening. BARNES \& NOBLE, INC.

Puguh, R. D. (2000). Penataan Kesenian Gambang Semarang Sebagai Identitas Budaya Semarang. Universitas Diponegoro.

Rachman, A., \& Utomo, U. (2019). The Rhythm Pattern Adaptation of Langgam Jawa in Kroncong. Dvances in Social Science, Education and Humanities Research, Volume 276 2nd International Conference on Arts and Culture (ICONARC 2018), 276(Iconarc 2018), 99-101.

Raharjo, E., \& Arsih, U. (2019). Gambang Semarang Music as A Cultural Identity Of Semarangs Community. 2nd International Conference on Arts and Culture (ICONARC 2018) Gambang, April. https://doi.org/10.2991/iconarc18.2019.8

Raharjo, E., Soesanto, S., Rohidi, T. R., \& Utomo, U. (2021). Preserving Gambang Semarang Music Through The Process of Enculturation in The Society. Harmonia: Journal of Arts Research and Education, 21(1), 60-67. https://doi.org/10.15294/harmonia.v21i1.27722 
Sadtiti, S. (2016). Gambang Semarang: Sebuah Identitas Budaya Semarang yang Termarginalkan. Jurnal Imajinasi, X(2), 143-151.

Salim, D. (1999). Respons Emotional Well-Being dalam Laras Gamelan Jawa. Mudra Jurnal Seni Budaya, 22(1), 139-150.

Sugimin, S. (2018). Mengenal Karawitan Gaya Yogyakarta. Keteg: Jurnal Pengetahuan, Pemikiran, Dan Kajian Tentang Bunyi, 18(November).

Suhaya, S., Rachman, A., Sinaga, S. S., \& Alfayad, D. M. (2020). Percussion pattern of terebang gede in panggung jati studio, panggung jati village, serang. Harmonia: Journal of Arts Research and Education, 20(2), 223-230.

https://doi.org/10.15294/harmonia.v20i2.18067

Supanggah, R. (2002). Bothekan Karawitan I. Ford Foundation \& Masyarakat Seni Pertunjukan Indonesia.

Supanggah, R. (2009). Bothekan Karawitan II: Garap (W. Waridi, Ed.). ISI Press Surakarta.

Utama, M. P., \& Puguh, D. R. (2013). Bertahan di Tengah Badai: Seni Pertunjukan Tradisi Semarangan. In Membedah Sejarah dan Budaya Maritim, Merajut Keindonesiaan. UNDIP Press.

Widodo, W., \& Suharto, S. (2017). Garap Greget Urip dalam Karawitan Jawa: Studi Kasus Garap Lelagon Campursari dalam Lomba Gending Dolanan RRI Surakarta. Unnes, Eprint-Sendratasik, September, 3-4. https://doi.org/10.31227/osf.io/bmq3r

Wimbrayardi, W., \& Parmadi, B. (2021). Variabilitas Tangga Nada Talempong Pacik Dalam Konteks Kesenian Tradisi Minangkabau. Mudra Jurnal Seni Budaya, 36(2), 135-139. https://doi.org/10.31091/mudra.v36i2.1438

Yuliati, D. (2013). Strengthening Indonesian National Identity Through History Semarang As a Maritime City: A Medium of Unity in Diversity. Humanika, $18(2)$. https://doi.org/10.14710/humanika.18.2 